\title{
Epigenetic Regulation in Early Childhood: A Miniaturized and Validated Method to Assess Histone Acetylation
}

\author{
Hani Harb ${ }^{a}$ Manori Amarasekera ${ }^{b}$ Sarah Ashley ${ }^{c}$ Meri K. Tulic ${ }^{b}$ e \\ Petra Ina Pfefferle ${ }^{a}$ Daniel P. Potaczek ${ }^{a} \quad$ David Martino $^{c, d}$ Dörthe A. Kesper ${ }^{a}$ \\ Susan L. Prescott ${ }^{b}$ Harald Renz ${ }^{a}$ \\ a Institute of Laboratory Medicine, Pathobiochemistry and Molecular Diagnostics, Philipps University Marburg,

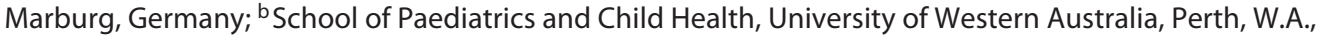 \\ 'Murdoch Childrens Research Institute, and ' Department of Paediatrics, University of Melbourne, Parkville, Vic.,

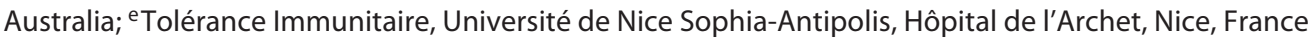

\section{Key Words}

Chromatin immunoprecipitation - Epigenetic regulation .

Neonates · CD4+ T cells · Histone acetylation · Allergy

\begin{abstract}
Introduction: Chronic inflammatory diseases including allergies and asthma are the result of complex interactions between genes and environmental factors. Epigenetic mechanisms comprise a set of biochemical reactions that regulate gene expression. In order to understand the cause-effect relationship between environmental exposures and disease development, methods capable of assessing epigenetic regulation (also) in large cohorts are needed. Methods: For this purpose, we developed and evaluated a miniaturized chromatin immunoprecipitation (ChIP) assay allowing for a costeffective assessment of histone acetylation of candidate genes in a quantitative fashion. This method was then applied to assess $\mathrm{H} 3$ and $\mathrm{H} 4$ histone acetylation changes in cord blood (CB) samples from an established cohort of Australian children exposed in the fetal period to either very low or very high levels of maternal folate. Results: Our ChIP assay
\end{abstract}

was validated for a minimum requirement of $1 \times 10^{5}$ target cells (e.g. CD4+ T cells). Very high levels of maternal folate were significantly associated with increased $\mathrm{H} 3 / \mathrm{H} 4$ acetylation at GATA3 and/or IL9 promoter regions in CD4+ T cells in CB. Conclusion: We developed a ChIP method allowing reliable assessment of $\mathrm{H} 3 / \mathrm{H} 4$ acetylation using $1 \times 10^{5}$ cells only. Practical application of this assay demonstrated an association between high maternal folate exposure and increased histone acetylation, corresponding to a more transcriptionally permissive chromatin status in the promoter regions of some Th2-related genes. $\quad 2016 \mathrm{~S}$. Karger AG, Basel

\section{Introduction}

Effective immune development in early life is important for the prevention of chronic inflammatory diseases such as allergies and asthma. Complex changes in gene-

H.H., M.A., S.L.P. and H.R. contributed equally to this work.

\section{KARGER 125\%}

(c) 2016 S. Karger AG, Base

$1018-2438 / 16 / 1683-0173 \$ 39.50 / 0$

E-Mail karger@karger.com

www.karger.com/iaa
Correspondence to: Prof. Harald Renz

Institute of Laboratory Medicine

Philipps University Marburg, Germany

Baldingerstrasse, DE-35043 Marburg (Germany)

E-Mail renzh@med.uni-marburg.de 
environment interactions are responsible for disease development. Environmental factors modulate gene expression through epigenetic mechanisms, including DNA methylation, histone modifications and other biochemical changes [1]. Different techniques have been established to analyze epigenetic marks. The chromatin immunoprecipitation (ChIP) method has been developed to assess histone modifications including acetylation and methylation in a quantitative fashion $[2,3]$. However, it is still difficult to apply this method in large-cohort studies due to its challenging nature, some technical obstacles and substantial costs [4].

This study was performed to miniaturize and validate a modified and cost-effective ChIP assay of histone acetylation to ensure the high quality of the data obtained from a relatively small number of target cells. The performance of our method was assessed by determination of the lower limit of detection (LLOD), the lower limit of quantification (LLOQ) and the reference range for several gene loci and analysis of the inter- and intra-assay coefficient of variance as well as testing the freeze-thaw stability and observing the effects of working temperature or longterm storage of the samples. As our main interest was to obtain information on epigenetic changes at loci known to be involved in the development of chronic inflammatory disease, we focused on selected Th1-, Th2-, Th17- or Treg-specific genes expressed in CD4+ T cells. Subsequently, this protocol was validated in cord blood (CB) samples from an established cohort of Australian children exposed either to very low or very high maternal folate levels [5].

\section{Methods}

First Study Population for Method Validation

The study group consisted of 10 healthy adults ( 5 females), i.e. individuals in whom allergies and other chronic diseases had been excluded. The study was approved by the Ethics Committee of the Philipps University Marburg Medical Faculty.

\section{Second Study Population for Method Validation}

The design of the folate study was described in detail previously [5]. In brief, 628 mother-infant pairs were recruited through the Allergy Research Clinic in the Princess Margaret Hospital for Children, Perth, W.A. Australia, during the last trimester $(\geq 28$ weeks) of pregnancy, at which time maternal blood samples were drawn. CB samples were taken at the time of birth. CB mononuclear cells were harvested from blood samples within $12 \mathrm{~h}$ from collection according to standard protocols. Serum folate measurements were available for 435 maternal and 285 CB samples. Extensive clinical, dietary, maternal antenatal and socio-demographic data obtained at recruitment were also accessible.
From this study, a sample population of 23 neonates was selected, based on the negativity of skin-prick testing for a range of inhalant and dietary allergens and a lack of clinically assessed development of allergic disorder within the first year of life as well as the availability of matched samples of maternal blood and CB. The high-folate (HF) and low-folate (LF) groups were defined according to the first and third quartiles from the distribution of maternal serum folate levels in conventional extremes of exposure design [5]. The children of mothers who smoked during pregnancy or those showing evidence of congenital birth defects were also excluded. Since vitamin D levels were higher in the HF group ( $\mathrm{p}=$ 0.04) [5], all subsequent analyses were adjusted for any potential effect of vitamin D. All study procedures were carried out in accordance with full institutional ethics.

\section{Serum Folate Measurement}

Folate levels were measured in maternal blood and CB serum using a competitive immunoassay (Immulite 2000; Siemans Medical Solutions Diagnostics, Flanders, N.J., USA) [6].

\section{Isolation of CD4+ T Cells}

CD4+ T cells were isolated from CB mononuclear cells (CBMC) using a 2-step isolation strategy with magnetic DYNAL beads (Invitrogen, Noble Park North, Vic., Australia). CBMC were incubated with $\mathrm{CD} 8+$ magnetic beads (Invitrogen, Carlsbad, Calif., USA), and the CD8 - fraction was then incubated with CD4+ magnetic beads according to the manufacturer's recommendations. Routine purity tests were conducted by flow cytometry using the following antibodies: CD19-FITC, CD3-PE, CD8-PerCP, CD11cPE Cy7, CD4-APC and CD14-APC Cy7 (BD Biociences, San Jose, Calif., USA) with appropriate istoype controls. CD4+ cell purities ranged from 89 to $96 \%$. A fraction of isolated CD4+ T cells was frozen with $15 \%$ dimethyl sulphoxide in heat-inactivated fetal calf serum and stored in liquid nitrogen until being transported to Marburg, Germany, for ChIP analysis.

\section{Preparation of the CD4+ T Cell Chromatin for Chromatin Immunoprecipitation}

For cross-linking of the histones with DNA, CD4+ cells were fixed at room temperature (RT) using $1 \%$ formaldehyde for $8 \mathrm{~min}$. The reaction was stopped with $2.5 \mathrm{M}$ glycine. Subsequently, to prevent deacetylation by different histone deacetylases (HDAC), the chromatin was treated for 3 min with $5 \mathrm{M}$ sodium butyrate, an HDAC inhibitor, and then centrifuged at 8,000 $\mathrm{g}$ at RT for $5 \mathrm{~min}$. Next, cells were incubated with lysis buffer I (online suppl. table 1; see www.karger.com/doi/10.1159/000442158 for all online suppl. material) at RT for $20 \mathrm{~min}$. After centrifugation at $8,000 \mathrm{~g}$ at RT for $5 \mathrm{~min}$, the chromatin was incubated with lysis buffer II containing $1 \%$ sodium dodecyl sulfate (SDS; online suppl. table 1) at RT for $5 \mathrm{~min}$ and on ice for $3 \mathrm{~min}$. Chromatin was then placed directly in the power-up Bioruptor (Diagenode, Liège, Belgium) for 30 cycles, where each cycle was on for $30 \mathrm{~s}$ and off for $30 \mathrm{~s}$ (high power). Afterwards, the chromatin was centrifuged for $15 \mathrm{~min}$ at $13,000 \mathrm{~g}$ to remove any debris that could potentially interfere with further procedures. The supernatant was transferred to a new reaction tube and diluted in SDS to a concentration of $0.1 \%$.

Assessment of the Chromatin Sonication Efficiency

To analyze the chromatin sonication efficiency, samples were run for $1 \mathrm{~h}$ on $1.5 \%$ agarose gel at $120 \mathrm{~V}$. 
Assessment of Immune Responses

Cryopreserved stocks of CBMC were gently thawed in RPMI media (Invitrogen) and briefly treated with DNase I ( $5 \mu \mathrm{g} / \mathrm{ml}$; Sigma-Aldrich, Taufkirchen, Germany) for 10 min to digest extracellular DNA. Cells were washed and resuspended to a concentration of $1 \times 10^{6}$ cells $/ \mathrm{ml}$ in RPMI- 1640 culture medium (Thermo Scientific, Waltham Mass., USA) and seeded in 96-well polystyrene plates (Thermo Scientific). For assessment of immune responses, CBMC were cultured alone or with optimized concentrations of ovalbumin (OVA; $100 \mu \mathrm{g} / \mathrm{ml}$; Sigma-Aldrich) for $48 \mathrm{~h}$ in AIM-V media (Invitrogen) plus $\beta$-mercaptoethanol $\left(4 \times 10^{-5} \mathrm{M}\right)$. Lymphocyte cultures were maintained in $5 \% \mathrm{CO}_{2}$ at $37^{\circ} \mathrm{C}$ before supernatants were collected and stored at $-20^{\circ} \mathrm{C}$ for the subsequent quantification of cytokines (IL5, IL10, IL13, IFN $\gamma$ and TNF) with a Bioplex 200 system (Bio-Rad Laboratories, Gladesville, N.S.W., Australia). The lower limit of detection was $3 \mathrm{pg} / \mathrm{ml}$ for all the assays.

\section{Chromatin Immunoprecipitation}

For ChIP, sepharose beads (GE Healthcare Bio-Sciences, Uppsala, Sweden) were washed once with lysis buffer II and centrifuged at $1,800 \mathrm{~g}$ for $2 \mathrm{~min}$. After removal of the supernatant, the beads were blocked with $1 \mathrm{mg} / \mathrm{ml}$ BSA and $40 \mu \mathrm{g} / \mathrm{ml}$ salmon sperm DNA (Sigma-Aldrich) at $4^{\circ} \mathrm{C}$ overnight. The beads were then centrifuged at $1,800 \mathrm{~g}$ for $5 \mathrm{~min}$ and washed once with $5 \mathrm{ml}$ of lysis buffer II. A portion of $30 \mu \mathrm{l}$ of the beads per immunoprecipitation (IP) per number of samples were transferred to a new reaction tube and stored for later.

Then, $20 \mu$ of the beads per antibody per sample were added to the chromatin and incubated at $4{ }^{\circ} \mathrm{C}$ for $2 \mathrm{~h}$ for removal of chromatin nonspecifically bound to the sepharose beads (preclearing ' 1 '). After the incubation, the supernatant with the precleared chromatin was transferred to a new reaction tube $(1.5 \mathrm{ml})$.

The remaining beads were filled with $500 \mu \mathrm{l}$ of lysis buffer II per sample, and $1 \mu \mathrm{g}$ of an unspecific IgG antibody (Abcam, Cambridge, UK) was added to each sample. The beads with the unspecific antibody were incubated at $4^{\circ} \mathrm{C}$ for $1 \mathrm{~h}$. Afterwards, the beads coupled with IgG antibody were centrifuged at $1,800 \mathrm{~g}$ for $5 \mathrm{~min}$, washed 3 times with $5 \mathrm{ml}$ of lysis buffer II and centrifuged at $1,800 \mathrm{~g}$ for another $5 \mathrm{~min}$.

Next, $20 \mu \mathrm{l}$ of the IgG-coupled beads were added to the precleared chromatin from the remaining beads and incubated at $4{ }^{\circ} \mathrm{C}$ for another $2 \mathrm{~h}$ for the removal of chromatin unspecifically bound to IgG antibodies (preclearing ' 2 '). At the end of the incubation time, the precleared chromatin was centrifuged at $8,000 \mathrm{~g}$ at $4^{\circ} \mathrm{C}$ for $5 \mathrm{~min}$.

The supernatant containing the chromatin was transferred to a new reaction tube. One tenth of the chromatin volume was set aside as the input control. The $\mathrm{H} 3$ or $\mathrm{H} 4$ panacetyl antibodies ( $4 \mu \mathrm{g}$; Millipore, Darmstadt, Germany) were added to the chromatin and incubated at $4{ }^{\circ} \mathrm{C}$ overnight. A negative-control IgG was also prepared ( $0.5 \mu \mathrm{g}$; Abcam, Cambridge, UK).

Afterwards, $30 \mu \mathrm{l}$ of the beads that had been saved were added to each IP and then incubated at $4^{\circ} \mathrm{C}$ for $2 \mathrm{~h}$. Once the incubation was complete, the beads were centrifuged at $8,000 \mathrm{~g}$ for $2 \mathrm{~min}$ and washed twice with wash buffer I, twice with wash buffer II, 3 times with wash buffer III and finally twice with $1 \times$ TE buffer (online suppl. table 1). After discarding the supernatant, $500 \mu$ lof the elution buffer were added to the sepharose beads, vortexed and incubated at RT for $30 \mathrm{~min}$. The mixture was then centrifuged at
$8,000 \mathrm{~g}$ for $2 \mathrm{~min}$. The supernatant contained the precipitated chromatin and was transferred to a new reaction tube.

To reverse the cross-linking, the following mixture was added to the IP product as well as to the input controls saved from above: $20 \mu \mathrm{l}$ of $5 \mathrm{M} \mathrm{NaCl}, 10 \mu \mathrm{l}$ of $0.5 \mathrm{M}$ EDTA ( $\mathrm{pH} 8.0$ ), $20 \mu \mathrm{l}$ of $1 \mathrm{M}$ Tris ( $\mathrm{pH} 7.2), 1 \mu \mathrm{l}$ of proteinase $\mathrm{K}(20 \mathrm{mg} / \mathrm{ml}$; Sigma-Aldrich) and $1 \mu \mathrm{l}$ of RNase A (10 mg/ml; Sigma-Aldrich).

The samples were first incubated at $55^{\circ} \mathrm{C}$ for $3 \mathrm{~h}$ and then at $65^{\circ} \mathrm{C}$ overnight. Afterwards, the DNA was purified using QIAquick PCR purification kit (Qiagen, Hilden, Germany) according to the manufacturer's instructions. The purified DNA was used in real-time PCR to measure the enrichment of promoter regions in several genes listed along with relevant primers in online supplementary table 2 . The enrichment was calculated using the following formula:

$$
\% \text { enrichment }=100 \times 2^{[(\mathrm{CT} \text { input }-3.3)-\mathrm{CT} \text { sample }]}
$$

Of the 2 typically used percentages of starting chromatin used as an input, i.e. 1 and $10 \%$, the latter was used in the currently reported method. For the input fraction of $10 \%$, a dilution factor (DF) of 10 or 6.3 cycles (i.e. $\log _{2}$ of 10 ) was subtracted from the $\mathrm{Ct}$ value of diluted input.

The percent enrichment of the negative control (IgG) was subtracted from this value and then normalized to the RPL32 housekeeping gene (HKG). The advantage of the application of a HKG measurement method is that the same ChIP samples are used to analyze both sequences of interest and control sequences, eliminating variation caused by sample handling. The normalization was done according to the following formula:

normalized enrichment to desired gene $=$

$\%$ enrichment to desired gene/\% enrichment to HKG [7].

\section{Statistical Analysis}

Direct comparisons of acetylation levels between the LF and HF groups were conducted using multiple linear regression in which continuous variables having distribution other than normal according to the Shapiro-Wilk test (positively skewed in all cases) were approximated to normality by square root transformation before entering the model. Since vitamin D levels varied between the 2 groups [5], this was a potential confounder and adjustment for it was included in all analyses. $\mathrm{p}<0.05$ was considered statistically significant. Analyses were performed using Statistica v8.0 software (StatSoft, Tusla, Okla., USA).

\section{Results}

\section{Establishment and Validation of the ChIP Method}

Analysis of epigenetic marks by ChIP assay requires fixation of the molecular complex, containing proteins and DNA, by cross-linking with formaldehyde before the chromatin undergoes shearing by sonication to obtain fragments ranging from 100 to $1,000 \mathrm{bp}$. Subsequently, IP is performed with specific antibodies directed against the protein of interest. This step is followed 


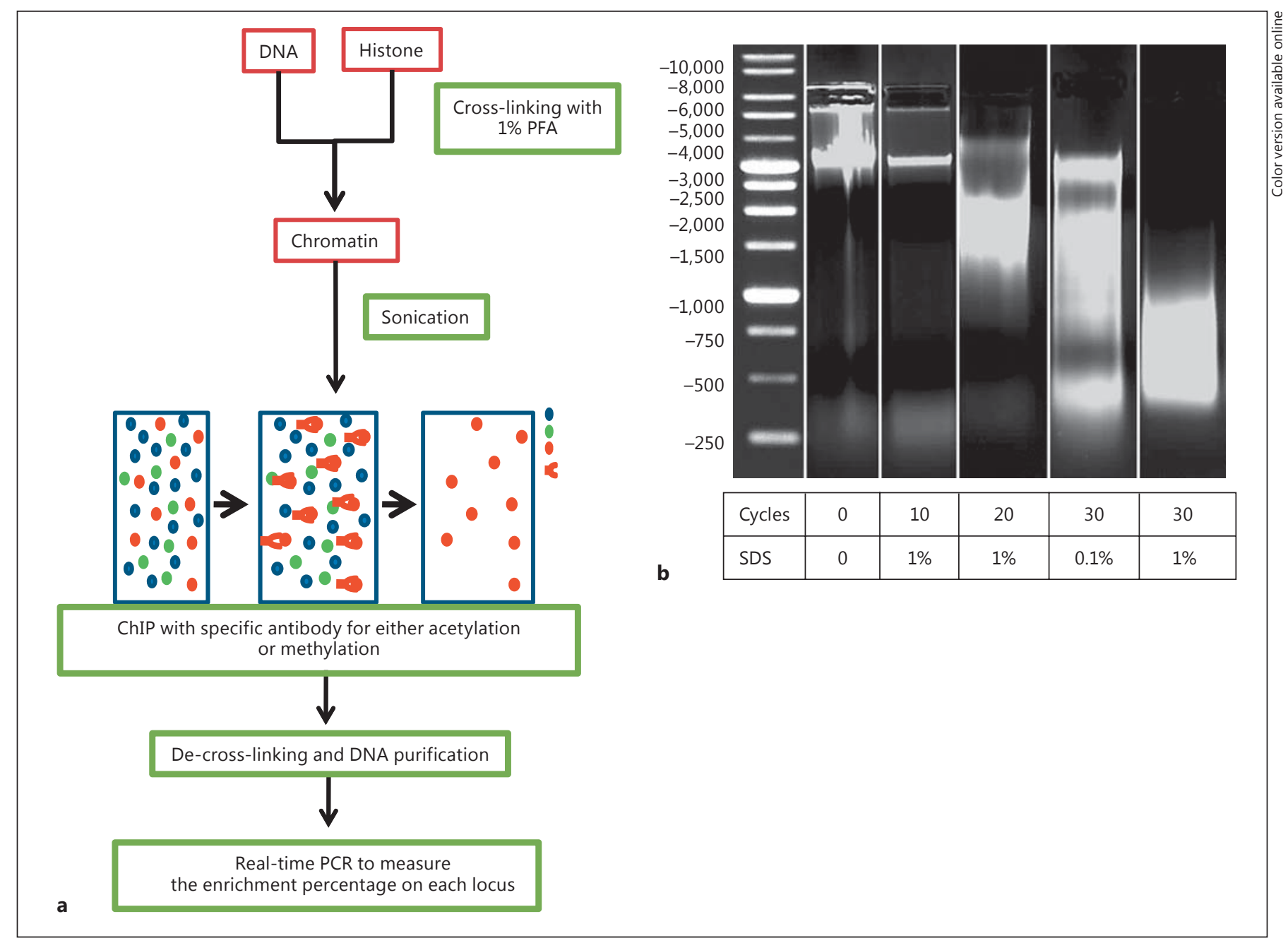

Fig. 1. ChIP assay outline and shearing efficiency optimization. a Flowchart for the ChIP method. b Shearing efficiency of human CD4+ T cells was tested using different SDS concentrations ranging from 0.1 to $1 \%$ and varying numbers (10-30) of the Bioruptor sonication cycles, each $30 \mathrm{~s} / 30 \mathrm{~s}$ on/off.

by de-cross-linking of the chromatin, and DNA purification before the enrichment of certain DNA fragments is analyzed by quantitative real-time PCR (fig. 1a). Critical steps in this protocol are the fixation time and the mode of sonication. This is particularly the case for nonactivated CD4+ T cells, which are the major portion of CD4+ T cells in peripheral blood samples, as these cells have a highly compact, relatively resistant-to-sonication chromatin structure [7]. We tested several SDS concentrations and sonication techniques using the Bioruptor sonicator, and found that a relative high SDS concentration (1\%) was required with sonication on-off cycles of $30 \mathrm{~s}$ each for $30 \mathrm{~min}$ using a high power to produce fragments of the desired length (fig. 1b). For the next steps of the ChIP procedure, the SDS concentration in the sample should not exceed $0.1 \%$, so the sample was diluted accordingly.

\section{Reference Range and Coefficient of Variance}

The reference range from healthy individuals is used to differentiate the variation of histone modifications within the normal population in a distinct cell type [7]. The reference range for each gene was determined in CD4+ T cells purified from the blood of 10 healthy individuals $[6,8]$. Gene loci of interest were IFNG, TNF (Th1 cells), IL4, IL5, IL9, IL13, GATA3 (Th2 cells), IL17 (Th17 cells), IL10 and FOXP3 (Treg cells). Since it is associated with activating histone marks in all cells, the RPL32 gene 
Table 1. LLOD, reference range, and intra- and inter-assay coefficient of variance of the ChIP assay applied for different loci

\begin{tabular}{|c|c|c|c|c|c|c|c|c|}
\hline$I F N G$ & 0.001 & $0.001-2.12$ & 0.001 & 4.23 & 0.001 & $0.12-1.42$ & 1.25 & 9.36 \\
\hline IL4 & 0.001 & $0.5-1.4$ & 15.23 & 9.36 & 0.001 & $0.92-4.7$ & 0.001 & 7.36 \\
\hline IL5 & 0.001 & $0.001-0.93$ & 0.001 & 0.001 & 0.001 & $0.12-1.32$ & 0.001 & 0.001 \\
\hline IL13 & 0.2 & $0.2-0.84$ & 0.001 & 3.36 & 0.13 & $0.14-0.53$ & 5.36 & 5.89 \\
\hline FOXP3 & 0.06 & $0.06-1.06$ & 9.2 & 9.54 & 0.001 & $0.001-0.35$ & 9.6 & 5.22 \\
\hline TNF & 0.001 & $0.001-2.1$ & 8.18 & 9.78 & 0.001 & $0.23-0.6$ & 3.36 & 10.47 \\
\hline MS4A2 & 0.001 & 0 & - & - & 0 & 0 & - & - \\
\hline
\end{tabular}

${ }^{1}$ LLOD determined by measuring blank samples $(n=5) .{ }^{2}$ Reference range measured using the $95 \%$ confidence interval of the geometric mean $\left(n=10\right.$ healthy donors). ${ }^{3}$ Intra-assay coefficient of variance: measuring 1 sample at several times in 1 run to test the accuracy of the method ( $\mathrm{n}=10$ healthy donors). ${ }^{4}$ Inter-assay coefficient of variance: measuring 1 sample at several times in different runs to test for the precision of the method ( $n=10$ healthy donors).

was chosen as a positive control [7], while MS4A2 (encoding FceRI $\beta$; inactive in CD4+ T cells) was used as a negative control. ChIP was performed with antibodies directed against $\mathrm{H} 3$ and $\mathrm{H} 4$ acetylation. We found that RPL32 is always associated with acetylated histone marks (0.5$3 \%$ input for $\mathrm{H} 3$ and $0.12-3.7 \%$ input for $\mathrm{H} 4$ ), while we could not detect any enrichment of acetylated histones at the MS4A2 locus. The reference ranges for all analyzed loci are listed in table 1.

Inter- and intra-assay coefficients of variance, assessed for both $\mathrm{H} 3$ and $\mathrm{H} 4$ histones, were $<10 \%$ for all of the genes except IL4 and TNF (table 1).

\section{Lower Limit of Quantification and Lower Limit of Detection}

The LLOQ is the lowest number of cells required in the ChIP protocol to deliver acceptable reliable data. The number of cells used in most published protocols is approximately $2 \times 10^{6}[9,10]$; to determine the lowest number of CD4+ T cells required for obtaining reliable enrichment values, we titrated this down to $10^{4}$. The results (fig. 2a) indicated that the ChIP loses its detection power at a CD4+ T cell number below $1 \times 10^{5}$, determining the LLOQ value.

The LLOD is defined as the lowest quantity of a substance that is distinguished from its absence reflecting the background of the test [7]. Here, the LLOD was determined using 5 blanks. The LLOD for most of the samples was $<0.001 \%$ for both $\mathrm{H} 3$ and $\mathrm{H} 4$ acetylation. Some genes showed an increased background level with a higher LLOD, e.g. IL13 with an LLOD of 0.2 or $0.13 \%$ for histone $\mathrm{H} 3$ or $\mathrm{H} 4$, respectively, and the highest LLOD of $0.06 \%$ was detected for $\mathrm{H} 3$ histone in FOXP3 (table 1).

\section{Freezing/Thawing of the Samples Impairs \\ Chromatin Quality}

To assess if thawing of the previously frozen samples might influence the chromatin stability and thus the results of the ChIP assay, aliquots of all samples obtained from the study population for method validation were frozen for $48 \mathrm{~h}$ in FCS with $10 \%$ DMSO at $-80^{\circ} \mathrm{C}$, and the histone acetylation estimation results were compared to those obtained using freshly isolated and processed aliquots of the same samples. There were no freezing/thawing-dependent differences in the enrichment of the studied loci.

\section{Storage Conditions Affect Chromatin Quality}

To test the influence of temperature on sample stability, the freshly fixed chromatin was left at RT for 3, 6, 12 and $24 \mathrm{~h}$ without the presence of any HDAC inhibitors, and the ChIP efficiency was compared in parallel to freshly processed chromatin from the same donor. Temperature-dependent effects were observed for several genes. A significant decrease in the enrichment percentage was detected in samples left at RT for $>3 \mathrm{~h}$ (fig. 2b). Furthermore, storage of samples at $-80^{\circ} \mathrm{C}$ for at least 30 days did not affect chromatin stability (data not shown). 


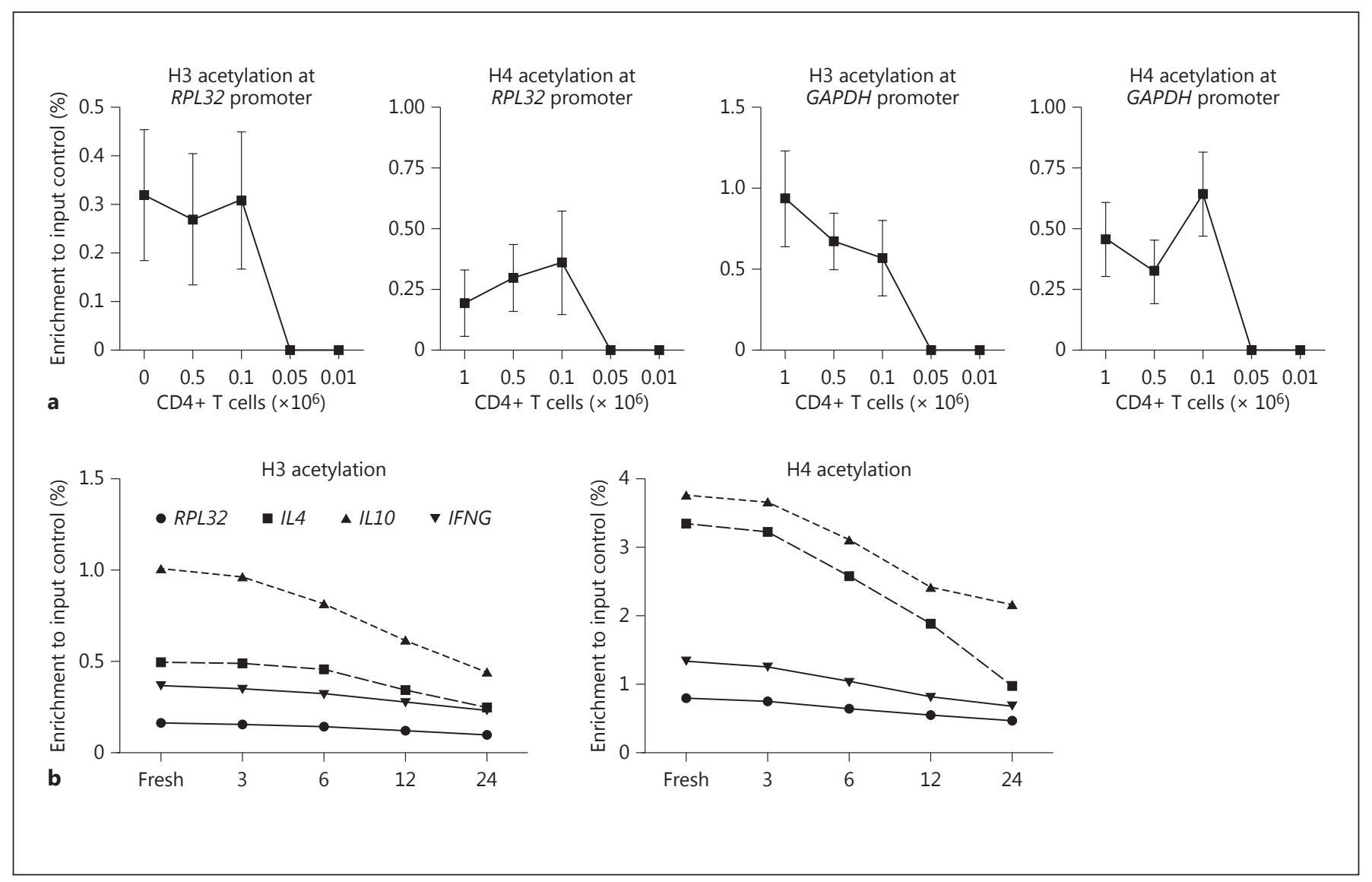

Fig. 2. Validation of our ChIP method. a The ChIP assay loses its detection power at $1 \times 10^{4} \mathrm{CD} 4+\mathrm{T}$ cells, indicating an LLOQ value of $1 \times 10^{5}$. Data are mean \pm SEM. b Temperature effect. Chromatin was extracted and ChIPed directly 3, 6, 12 and 24 h following cell isolation. Enrichment to input control at RPL32, IL4, IL10 and IFNG promoter loci was compared between different time points for both $\mathrm{H} 3$ and $\mathrm{H} 4$ histones.

\section{A High Maternal Folate Level Is}

Associated with Increased Acetylation of the GATA3

\section{Locus in Neonates}

To further validate our ChIP method, we analyzed the histone acetylation profile in CD4+ T cells collected from the $\mathrm{CB}$ of healthy neonates that differed in their prenatal exposure to maternal folate (i.e. LF vs. HF) and who remained nonatopic and nonallergic throughout the first year of life. Histone acetylation levels were analyzed at the indicated Th1, Th2, Th17 and Treg loci, and compared between children belonging to the LF or the HF group. The assays were performed under optimal conditions, determined in the above-described validation experiments (e.g. analysis of at least $1 \times 10^{5} \mathrm{CD} 4+$ T cells).

Figure 3 shows the results of this comprehensive analysis. Significant differences between study groups were de- tected only for GATA3 and IL9. Acetylation levels at the GATA3 promoter region in the HF group were significantly higher in both $\mathrm{H} 3$ and $\mathrm{H} 4$ histones $(\mathrm{p}<0.05)$ compared to the others. The HF group demonstrated a tendency towards higher $\mathrm{H} 3$ acetylation levels at the IL9 locus in comparison with LF neonates ( $p=0.074$; fig. $3 a$ ), which reached full statistical significance for the $\mathrm{H} 4$ histone $(\mathrm{p}<$ 0.05; fig. 3b). Moreover, acetylation of the $\mathrm{H} 4$ histone in this group tended to be higher at the IL13 locus ( $\mathrm{p}=0.085$ ) and lower in the case of the IFNG gene ( $\mathrm{p}=0.086$; fig. $3 \mathrm{~b}$ ). Between-group differences in histone modifications at the promoter regions of Th2-associated genes suggest the chromatin state to be more poised towards eliciting Th2 immune responses in neonates exposed to high maternal folate in utero. Indeed, IL5, IL13 and TNF production following CBMC stimulation with OVA turned out to be higher in the HF group; however, in the case of IFN $\gamma$, the 


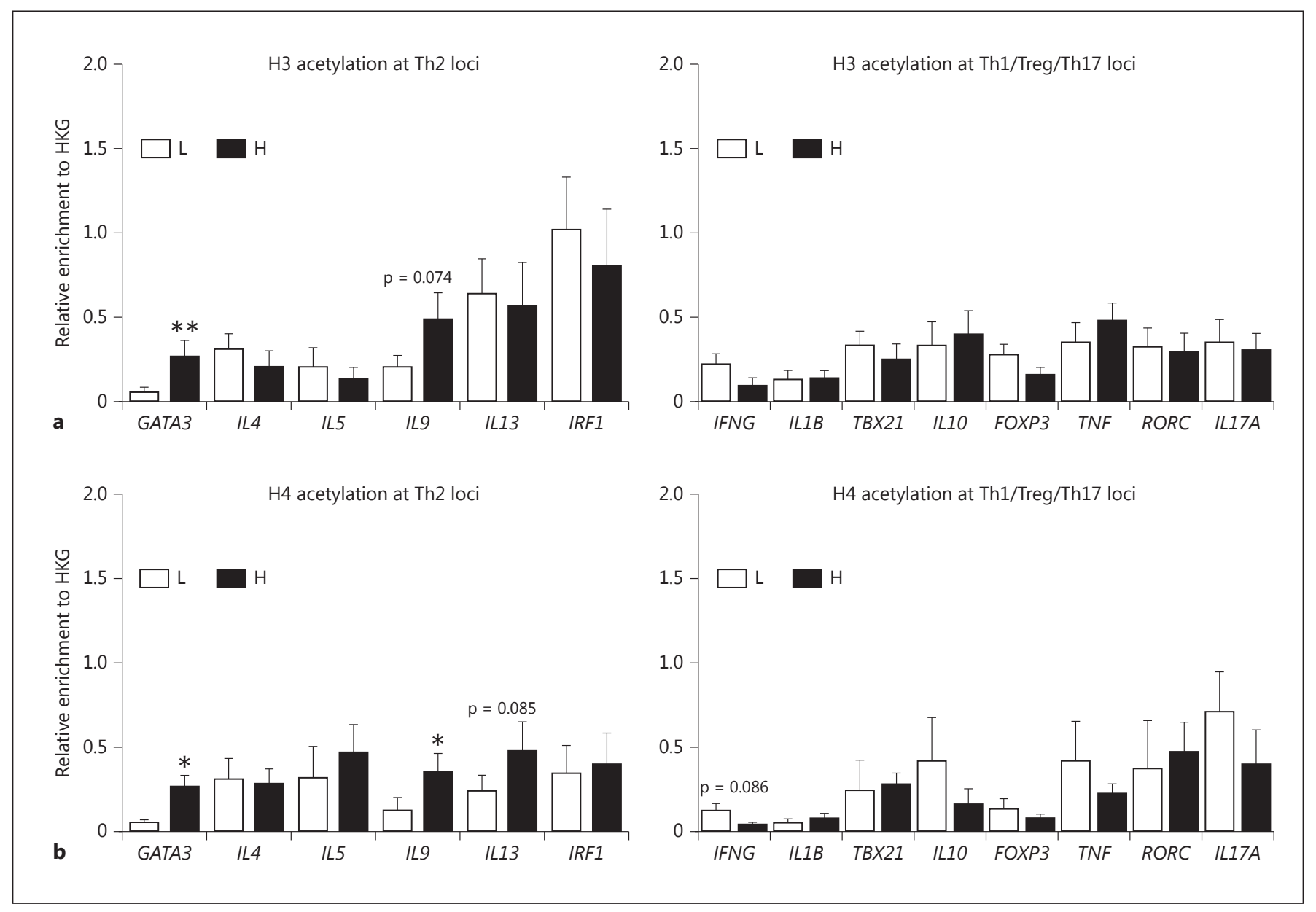

Fig. 3. Th1, Th2, Treg and Th17 locus histone acetylation profile in CB CD4+ T cells obtained from $\mathrm{HF}(\mathrm{H} ; \mathrm{n}=$ 12) versus $L F(L ; n=11)$ neonates. a $H 3$ histone. b H4 histone. Results are expressed as relative enrichment after normalization to RPL32 as mean \pm SEM. ${ }^{*} \mathrm{p}<0.05 ;{ }^{* *} \mathrm{p}<0.01$.

elevated levels seen in the OVA-stimulated CMBC from the $\mathrm{HF}$ neonates suggest that $\mathrm{H} 3 / \mathrm{H} 4$ acetylation is not a main driver of IFN $\gamma$ synthesis (fig. 4).

\section{Discussion}

The ChIP protocol presented here was adapted from those published previously [9-11] and was optimized for human CD4+ T cells. These cells play a prominent role in the pathogenesis of chronic inflammatory disease including allergies and autoimmunity [12-14]. The most challenging part of the protocol was to define the optimal shearing efficiency for CD4+ T cells that are isolated directly from peripheral blood. This cell population contains a large number of nonactivated CD4+ T cells, with highly condensed chromatin that is relatively resistant to sonication [15]. In order to obtain the best chromatin shearing efficiency without damage, we experimentally compared various protocols. An optimum was reached with (1) $1 \%$ SDS concentration in the lysis buffer II, (2) 30 -min sonication in the Bioruptor sonicator with 30 -second on/off cycles and (3) a constant temperature of $4^{\circ} \mathrm{C}$.

Validation of our method by calculation of both the inter- and intra-assay coefficients of variance yielded acceptable results. As the number of cells available in clinical studies is often limited, especially in cases involving children, we carefully optimized the LLOQ, which is the lowest concentration at which an analyte could be reliably measured. In many studies, the reported number of cells needed for the ChIP assay to function was about 2 million $[4,9,16,17]$. We demonstrate here that this could effec- 


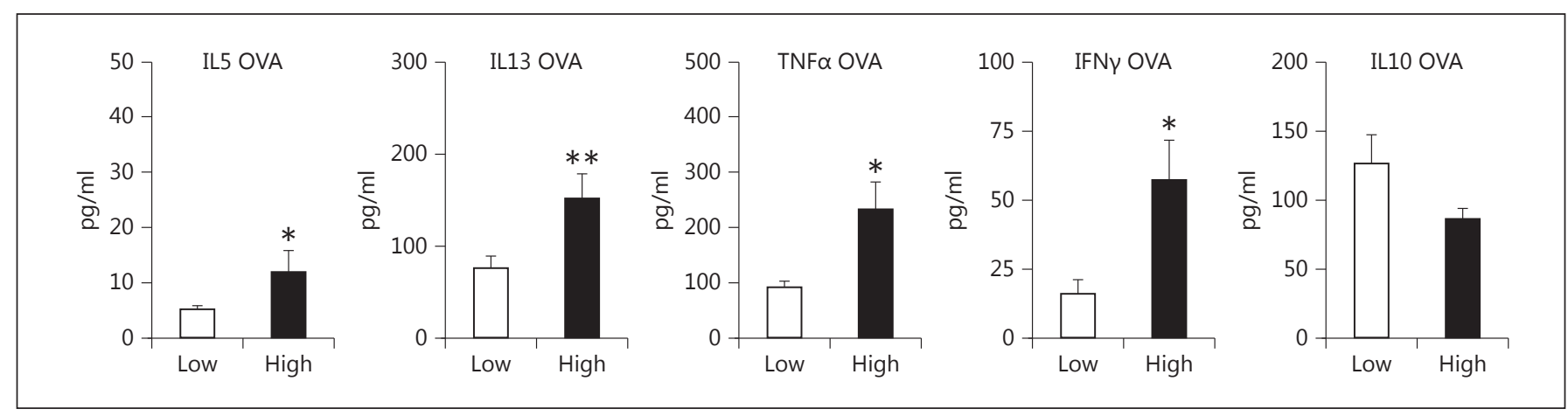

Fig. 4. Cytokine production by OVA-stimulated CBMC. Cells from both the low LF and HF groups were stimulated with OVA for $48 \mathrm{~h}$. Supernatants were isolated and a set of Th1 and Th2 cytokines was measured. Results are mean \pm SEM. ${ }^{*} \mathrm{p}<0.05 ;{ }^{* *} \mathrm{p}<0.01$.

tively be reduced to $1 \times 10^{5}$, and that only below this number our ChIP assay did start to lose its efficiency. One hundred thousand $\mathrm{CD} 4+\mathrm{T}$ cells can be readily isolated from $<1 \mathrm{ml}$ of blood, making it feasible to apply this protocol for the analysis of epigenetic modifications even in cohort studies on small children. An optimization of ChIP for $1 \times 10^{4}-10^{5}$ cells has already been reported, but primarily for tumor cell lines [18], in which the ChIP procedure is technically much easier than in T cells, especially CD4+ T cells. Since our aim was to establish a universal protocol, potentially usable in multiple cell types, our method was optimized and validated using the 'difficult' cell subset of CD4+ T cells. In addition, some commercial kits for ChIP analysis of $1 \times 10^{5}$ or smaller numbers of cells will become available on the market. In comparison to these, our method is much cheaper, and costeffectiveness was another goal of our study.

All preanalytical steps require particular care. This includes storage conditions of (a subset of) collected cells, preferably at $-80^{\circ} \mathrm{C}$, and the time and temperature conditions between cell separation and analysis, which should be kept $<3 \mathrm{~h}$ and at $4^{\circ} \mathrm{C}$, respectively. Moreover, an appropriate fixation of the chromatin ensures its subsequent quality, and the use of sodium butyrate inhibits all the different HDAC, thus protecting the stability of the histone acetylation marks. In the analysis conducted on the $\mathrm{CB}$ $\mathrm{CD} 4+\mathrm{T}$ cells of neonates, a significant association between maternal folate level and increased histone acetylation at the GATA3 (H3 and H4) and IL9 (H4) loci was observed. The GATA3 gene encodes the master transcription factor for the development of Th2 cells [19-21], while IL9 is a cytokine predominantly produced by Th 2 and Th9 cells $[22,20,23]$. Together with respective changes in some Th2 cytokines observed at protein level, these findings might suggest that the high gestational folate exposure in CD4+ T cells is associated with the more transcriptionally permissive chromatin status at the promoter regions of Th2-associated genes. This pilot investigation lays thus the ground for further prospective studies that aim to firmly establish the relationship between maternal folate exposure and the maturation of $\mathrm{T}$ cell subsets and its potential influence on allergy development in children.

In conclusion, we established a ChIP method to assess histone acetylation in CD4+ T cells suitable for large longitudinal and cross-sectional studies with special requirements for sample handling. We also confirmed that our assay is reliable for the detection of prenatal folate exposure-related differences in histone modifications at the promoter regions of several immunoregulatory genes.

\section{Acknowledgements}

All authors are members of International Inflammation (in-FLAME) Network, Worldwide Universities Network (WUN). The work was supported by the LOEWE Excellence Centre UGMLC (Universities of Giessen and Marburg Lung Centre), the Deutsches Zentrum für Lungenforschung (DZL) and the Deutsche Forschungsgemeinschaft (SFB/TR22).

\section{Disclosure Statement}

The authors declare that they have no relevant conflicts of interest. 


\section{References}

1 Renz H, von Mutius E, Brandtzaeg P, Cookson WO, Autenrieth IB, Haller D: Gene-environment interactions in chronic inflammatory disease. Nat Immunol 2011;12:273-277.

2 Das PM, Ramachandran K, vanWert J, Singal R: Chromatin immunoprecipitation assay. Biotechniques 2004;37:961-969.

3 Marcon E, Jain H, Bhattacharya A, Guo H, Phanse S, et al: Assessment of a method to characterize antibody selectivity and specificity for use in immunoprecipitation. Nat Methods 2015;12:725-731.

4 Dahl JA, Klungland A: Micro chromatin immunoprecipitation ( $\mu \mathrm{ChIP}$ ) from early mammalian embryos. Methods Mol Biol 2015; 1222:227-245.

5 Amarasekera M, Martino D, Ashley S, Harb H, Kesper D, Strickland D, Saffery R, Prescott SL: Genome-wide DNA methylation profiling identifies a folate-sensitive region of differential methylation upstream of ZFP57-imprinting regulator in humans. FASEB J 2014; 28:4068-4076.

6 Gosmaro F, Bagnati M, Berto S, Bellomo G, Prenesti E: Measurement of total antioxidant capacity of human plasma: setting and validation of the CUPRAC-BCS method on routine apparatus ADVIA 2400. Talanta 2013;115: 526-532.

7 Haring M, Offermann S, Danker T, Horst I, Peterhansel C, Stam M: Chromatin immunoprecipitation: optimization, quantitative analysis and data normalization. Plant Methods 2007;3:11.
8 Jones G, Barker A: Reference intervals. Clin Biochem Rev 2008;29(suppl 1):S93-S97.

9 Collas P: A chromatin immunoprecipitation protocol for small cell numbers. Methods Mol Biol 2011;791:179-193..

10 Strenkert D, Schmollinger S, Schroda M: Protocol: methodology for chromatin immunoprecipitation (ChIP) in Chlamydomonas reinhardtii. Plant Methods 2011;7:35.

11 Hezroni H, Tzchori I, Davidi A, Mattout A, Biran A, Nissim-Rafinia M, Westphal H, Meshorer E: H3K9 histone acetylation predicts pluripotency and reprogramming capacity of ES cells. Nucleus 2014;2:300-309.

12 Steinke JW, Lawrence MG: T-cell biology in immunotherapy. Ann Allergy Asthma Immunol 2014;112:195-199.

13 Yamane H, Paul WE: Early signaling events that underlie fate decisions of naive CD4+ T cells toward distinct T-helper cell subsets. Immunol Rev 2013;252:12-23.

14 Zhang Z, Sferra TJ, Eroglu Y: T cell co-stimulatory molecules: a co-conspirator in the pathogenesis of eosinophilic esophagitis? Dig Dis Sci 2013;58:1497-1506.

15 Rawlings JS, Gatzka M, Thomas PG, Ihle JN: Chromatin condensation via the condensin II complex is required for peripheral T-cell quiescence. EMBO J 2010;30:263-276.

16 Schnerch A, Rampalii S, Bhatia M: Histone modification profiling in normal and transformed human embryonic stem cells using micro chromatin immunoprecipitation, scalable to genome-wide microarray analyses. Methods Mol Biol 2013;1029:149-161.
17 O’Neill LP, VerMilyea MD, Turner BM: Epigenetic characterization of the early embryo with a chromatin immunoprecipitation protocol applicable to small cell populations. Nat Genet 2006;38:835-841.

18 Acevedo L, Leonardo Iniguez A, Holster H, Zhang X, Green R, Farnham P: Genome-scale ChIP-chip analysis using 10,000 human cells. Biotech 2007;43:791-797.

19 Barnes PJ: Role of GATA-3 in allergic diseases. Curr Mol Med 2008;8:330-334.

20 Cosmi L, Liotta F, Maggi E, Romagnani S, Annunziato F: Th17 and non-classic Th1 cells in chronic inflammatory disorders: two sides of the same coin. Int Arch Allergy Immunol 2014; 164:171-177.

21 Pniewska E, Sokolowska M, Kupryś-Lipińska I, Kacprzak D, Kuna P, Pawliczak R: Exacerbating factors induce different gene expression profiles in peripheral blood mononuclear cells from asthmatics, patients with chronic obstructive pulmonary disease and healthy subjects. Int Arch Allergy Immunol 2014;165: 229-243.

22 Schmitt E, Klein M, Bopp T: Th9 cells, new players in adaptive immunity. Trends Immunol 2014;35:61-68.

23 Ashjaei K, Bublin M, Smole U, Lengger N, Hafner C, Breiteneder H, Wagner S, Hoffmann-Sommergruber K: Differential T-helper cell polarization after allergen-specific stimulation of autologous dendritic cells in polysensitized allergic patients. Int Arch Allergy Immunol 2015;166:97-106. 